\title{
Mimicking microbial interactions under nitrate-reducing conditions in an anoxic bioreactor: enrichment of novel Nitrospirae bacteria distantly related to Thermodesulfovibrio
}

\author{
Arslan Arshad, ${ }^{1}$ Paula Dalcin Martins, ${ }^{2}$ \\ Jeroen Frank, ${ }^{1,3}$ Mike S. M. Jetten, ${ }^{1,3,4}$ \\ Huub J. M. Op den Camp ${ }^{1}$ and \\ Cornelia U. Welte (1) $1,3 *$ \\ ${ }^{1}$ Department of Microbiology, Institute for Water and \\ Wetland Research, Radboud University, Nijmegen, \\ The Netherlands. \\ ${ }^{2}$ Department of Microbiology, The Ohio State University, \\ Columbus, $\mathrm{OH}$, USA. \\ ${ }^{3}$ Soehngen Institute for Anaerobic Microbiology, \\ Radboud University, Nijmegen, The Netherlands. \\ ${ }^{4}$ Netherlands Earth Systems Science Center, Utrecht \\ University, Utrecht, The Netherlands.
}

\section{Summary}

Microorganisms are main drivers of the sulfur, nitrogen and carbon biogeochemical cycles. These elemental cycles are interconnected by the activity of different guilds in sediments or wastewater treatment systems. Here, we investigated a nitrate-reducing microbial community in a laboratory-scale bioreactor model that closely mimicked estuary or brackish sediment conditions. The bioreactor simultaneously consumed sulfide, methane and ammonium at the expense of nitrate. Ammonium oxidation occurred solely by the activity of anammox bacteria identified as Candidatus Scalindua brodae and $\mathrm{Ca}$. Kuenenia stuttgartiensis. Fifty-three percent of methane oxidation was catalyzed by archaea affiliated to $\mathbf{C a}$. Methanoperedens and $47 \%$ by $\mathrm{Ca}$. Methylomirabilis bacteria. Sulfide oxidation was mainly shared between two proteobacterial groups. Interestingly, competition for nitrate did not lead to exclusion of one particular group. Metagenomic analysis showed that the most abundant taxonomic group was distantly related to Thermodesulfovibrio sp. $(87-89 \%$

Received 11 August, 2017; revised 26 October, 2017; accepted 28 October, 2017. *For correspondence. E-mail c.welte@ science.ru.nl; Tel. (+31) 243652952.
16S rRNA gene identity, 52-54\% average amino acid identity), representing a new family within the Nitrospirae phylum. A high quality draft genome of the new species was recovered, and analysis showed high metabolic versatility. Related microbial groups are found in diverse environments with sulfur, nitrogen and methane cycling, indicating that these novel Nitrospirae bacteria might contribute to biogeochemical cycling in natural habitats.

\section{Introduction}

The biogeochemical nitrogen, carbon and sulfur cycles are interdependent on each other, particularly through the activity of microorganisms exchanging metabolites belonging to different cycles (Falkowski et al., 2008). In estuary or coastal anoxic sediments, reactive nitrogen compounds such as ammonium and nitrate discharged from agriculture can be present along with sulfide from the marine environment and methane from deeper methanogenic layers (Egger et al., 2015). Therefore, these ecosystems provide substrates for chemolithotrophic microorganisms involved in the nitrogen, carbon and sulfur cycles. Microorganisms that are capable of performing either partial or full denitrification can convert nitrate or nitrite to molecular nitrogen $\left(\mathrm{N}_{2}\right)$, thereby contributing to nitrogen loss from the ecosystem. Anammox bacteria are capable of $\mathrm{N}_{2}$ production by the anaerobic oxidation of ammonium $\left(\mathrm{NH}_{4}^{+}\right)$with nitrite $\left(\mathrm{NO}_{2}^{-}\right)$(van de Graaf et al., 1996). Nitrite is usually not supplied by agricultural discharge but produced during incomplete denitrification. In an estuary, coastal or brackish anoxic ecosystem, sulfide-dependent denitrification may release nitrite (Dong et al., 2000) or reduce nitrate completely to dinitrogen gas (Sorokin et al., 2008). Autotrophic sulfide-dependent denitrifiers have been found to supply nitrite to anammox bacteria in wastewater treatment plants (Mulder et al., 1995; van de Graaf et al., 1996), and this interaction might also occur in natural environments, e.g., marine oxygen minimum zones (Canfield et al., 2010). Indeed, when the interaction of anammox 
bacteria with autotrophic sulfide-dependent denitrifiers was studied in enrichment cultures mimicking marine oxygen minimum zones, it was found that the latter group provided nitrite for the anammox reaction (Russ et al., 2014; Toro and Cervantes, 2016). Besides sulfide, methane can also be oxidized during partial denitrification. Such activity has been demonstrated for the recently discovered nitratereducing anaerobic methanotrophic archaea tentatively named Candidatus Methanoperedens nitroreducens (Raghoebarsing et al., 2006; Haroon et al., 2013). Furthermore, bacterial anaerobic methanotrophs belonging to the $\mathrm{NC} 10$ clade tentatively named $\mathrm{Ca}$. Methylomirabilis oxyfera are capable of nitrite-dependent methane oxidation (Ettwig et al., 2010). They have been shown to co-exist with $\mathrm{Ca}$. M. nitroreducens where they compete for methane but cooperate for nitrite removal (Haroon et al., 2013). On the other hand, $\mathrm{Ca}$. M. oxyfera competes with anammox bacteria for their common substrate nitrite (Luesken et al., 2011; Shi et al., 2013). Under high electron donor to nitrogen ratios, nitrate may not be denitrified but instead be reduced to ammonium by a process termed dissimilatory nitrate reduction to ammonium (DNRA) (Kraft et al., 2011; van den Berg et al., 2015).

Investigating such interactions between nitrogen-, sulfurand methane-cycling microorganisms is relevant not only to understand natural ecosystems where denitrification is coupled to sulfide and methane oxidation but also to further develop the treatment of moderately saline wastewater produced by the pickling industry, in landfill leachate or through new technologies using sea water for toilet flushing (Xiao and Roberts, 2010).

In this study, we investigated the interactions of chemolithoautotrophic microorganisms involved in the methane, nitrogen and sulfur biogeochemical cycles in an anoxic laboratory-scale bioreactor that mimicked estuary, coastal or brackish sediment nutrient conditions. We monitored the composition of the microbial community as well as their substrate turnover in the bioreactor over a period of 382 days with physiological assays, fluorescence in situ hybridization imaging and metagenome sequencing. We observed that cross-feeding of nitrite and competition for nitrate and methane occurred between anammox bacteria, autotrophic sulfide-dependent denitrifiers and nitrate- and nitrite-dependent methanotrophs respectively. Surprisingly, we discovered that the most abundant member of the microbial community, comprising more than $24 \%$ of total metagenome reads, was a previously uncultured microorganism distantly related to Thermodesulfovibrio species (87-89\% 16S rRNA gene identity), representing a new family within the Nitrospirae phylum. A high quality draft genome was assembled and encoded complete respiratory pathways for oxygen, nitrate (DNRA and denitrification to $\mathrm{N}_{2} \mathrm{O}$ ), sulfate, dimethylsulfoxide and trimethylamine $\mathrm{N}$-oxide, alongside the putative ability to use a wide range of electron donors, i.e., formate, lactate, sulfur, acetate, pyruvate, hydrogen and carbohydrates. Its environmental distribution indicates that this bacterial group is involved in nutrient turnover in a wide range of nitrogen and sulfur cycling ecosystems.

\section{Results}

A denitrifying, methane-oxidizing and sulfide-oxidizing microbial community enriched in a laboratory-scale bioreactor system

A laboratory-scale bioreactor system was inoculated with biomass from a marine enrichment culture containing sulfide-dependent autotrophic denitrifiers and anammox bacteria (Russ et al., 2014) and mixed with biomass from a freshwater methane-oxidizing denitrification culture (Ettwig et al., 2016). The reactor received ammonium, nitrate, methane and sulfide in a $1 \% \mathrm{NaCl}$ mineral medium and was operated for 382 days. The reactor received $3 \mathrm{mmol}$ nitrate and $1.4 \mathrm{mmol}$ ammonium per day of which 2.3 and $1.2 \mathrm{mmol}$ were consumed respectively. Furthermore, the daily added $0.29 \mathrm{mmol}$ sulfide was almost completely consumed by the microbial community as the residual amount of sulfide in the bioreactor was less than $0.3 \mu \mathrm{mol}$. Methane oxidation rates could not be determined in the continuous bioreactor as the consumption was relatively low compared to the added methane flux. The methane oxidation rates were therefore determined in the bioreactor under batch mode. No nitrite was added to the bioreactor so that nitrite-depending microorganisms had to completely rely on the partial conversion of nitrate to nitrite by other microorganisms in the community. The apparent amount of nitrite in the bioreactor was less than $3 \mu \mathrm{mol}$, indicating a near complete conversion of produced nitrite. Ammonium was consumed through the anammox process, which is the only known pathway to anaerobically oxidize ammonium. As a control, samples retrieved from the bioreactor were tested for aerobic ammonium oxidation activity in a respiratory chamber; however, no activity could be observed (data not shown). Therefore, all ammonium was assumed to be converted by anammox bacteria leading to average ammonium and nitrite consumptions rates of 1.2 and $1.5 \mathrm{mmol}$ in $24 \mathrm{~h}$ in the $1.5 \mathrm{I}$ working volume of the bioreactor respectively. Additionally, nitrate is a byproduct of the anammox metabolism (Strous et al., 1998) and thus about $0.3 \mathrm{mmol}$ of nitrate would be recycled back into the system. Considering the additional nitrate produced by anammox, the net average nitrate consumption rate was 2.6 and not $2.3 \mathrm{mmol}$ in $24 \mathrm{~h}$. Eventually, the remainder of the produced nitrite would be consumed by nitrite-dependent methanotrophs.

Methane conversion rates were determined in batch mode of the bioreactor. During this test, no sulfide was added to the bioreactor so nitrate reduction would be 
exclusively dependent on anaerobic methane oxidizers. Heterotrophic denitrification was not tested as dead biomass would be the only organic carbon source for this process and, therefore, this activity was expected to be negligible. Reactor batch operation was started with $10 \%$ methane in the headspace, $10.95 \mathrm{mmol}$ nitrate and $483 \mu \mathrm{mol}$ ammonium. After $24 \mathrm{~h}$ of continuous batch operation, methane in the reactor headspace had decreased to $6.5 \%$ and nitrate to $7.65 \mathrm{mmol}$ (Fig. $1 \mathrm{~A}$ and $\mathrm{B}$ ), equalling a total consumption of $1.16 \mathrm{mmol}$ methane and $2.2 \mathrm{mmol}$ nitrate. Ammonium was already depleted after $12 \mathrm{~h}$ (Fig. 1C), after which a low amount of nitrite $(12 \mu \mathrm{mol})$ accumulated in the bioreactor.

\section{Fluorescence in situ hybridization and metagenomics analysis of the biomass}

Molecular characterization of the microbial community in the reactor was performed through fluorescence in situ hybridization (FISH) on day 63 and day 258 and by metagenome sequencing on day 258. After 63 days, FISH analysis showed the presence of the nitrate- and nitritedependent anaerobic methane oxidizers $\mathrm{Ca}$. M. nitroreducens and Ca. M. oxyfera (Fig. 2A). Furthermore, anammox bacteria as well as Sedimenticola sp., a gammaproteobacterial sulfide-dependent denitrifier, were detected (Fig. 2B). After 258 days, Ca. M. nitroreducens, Ca. M. oxyfera (Fig. 2C) and anammox bacteria could still be detected (Fig. 2F), whereas Sedimenticola sp. had disappeared (data not shown). Neither Sedimenticola-specific nor gammaproteobacterial probes resulted in a positive $\mathrm{FISH}$ signal. Instead, the betaproteobacterium Thiobacillus sp. (Fig. 2D) and other betaproteobacteria (Fig. 2E) had become abundant in the bioreactor.
Microbial community composition was examined through 16S rRNA gene analyses, uploading metagenome reads in the SILVA database project tool (Fig. 3A) and also by assembly and binning. This yielded 50 bins (Fig. 3B), including seven high quality bins to which over $50 \%$ of all sequencing data mapped. In line with the FISH results, we were able to assign genome bins to $\mathrm{Ca}$. M. nitroreducens, $\mathrm{Ca}$. M. oxyfera and the anammox bacteria $\mathrm{Ca}$. Kuenenia stuttgartiensis and $\mathrm{Ca}$. Scalindua brodae. These genome bins contained key genes for archaeal anaerobic methanotrophy, bacterial methanotrophy and the anammox reaction (Supporting Information Table S2) which have been described in detail elsewhere (Ettwig et al., 2010; van de Vossenberg et al., 2013; Arshad et al., 2015). It is interesting to note that $\mathrm{Ca}$. M. nitroreducens only made up $2 \%$ of the microbial community according to $16 \mathrm{~S}$ rRNA gene analyses (Fig. 3A), which contrasts the higher abundances indicated in the FISH micrographs (Fig. 2C). This may be due to DNA extraction biases that select against these archaea (Morono et al., 2009; Luo et al., 2014). Additionally, we identified three genome bins that showed the potential for sulfidedependent denitrification: two closely related to Sulfuricella denitrificans and one affiliated within the alphaproteobacterial family Phyllobacteriaceae. The most abundant putative sulfur oxidizer had a $98.53 \%$ complete draft genome with $0.87 \%$ contamination and a S3 protein (RpsC) $82.6 \%$ similar to the one in $S$. denitrificans skB26 (no 16S rRNA gene present). This genome revealed the presence of the complete sulfide oxidation and nitrate reduction pathways (Supporting Information Table S3). In this bin, we found the potential for sulfide conversion to elemental sulfur $\left(\mathrm{S}^{0}\right)$ or sulfite either by sulfide quinone reductase (Sqr) or the dissimilatory sulfite reductase complex (encoded by $d s r A B$ ) respectively. Sulfite can be further oxidized to adenosine
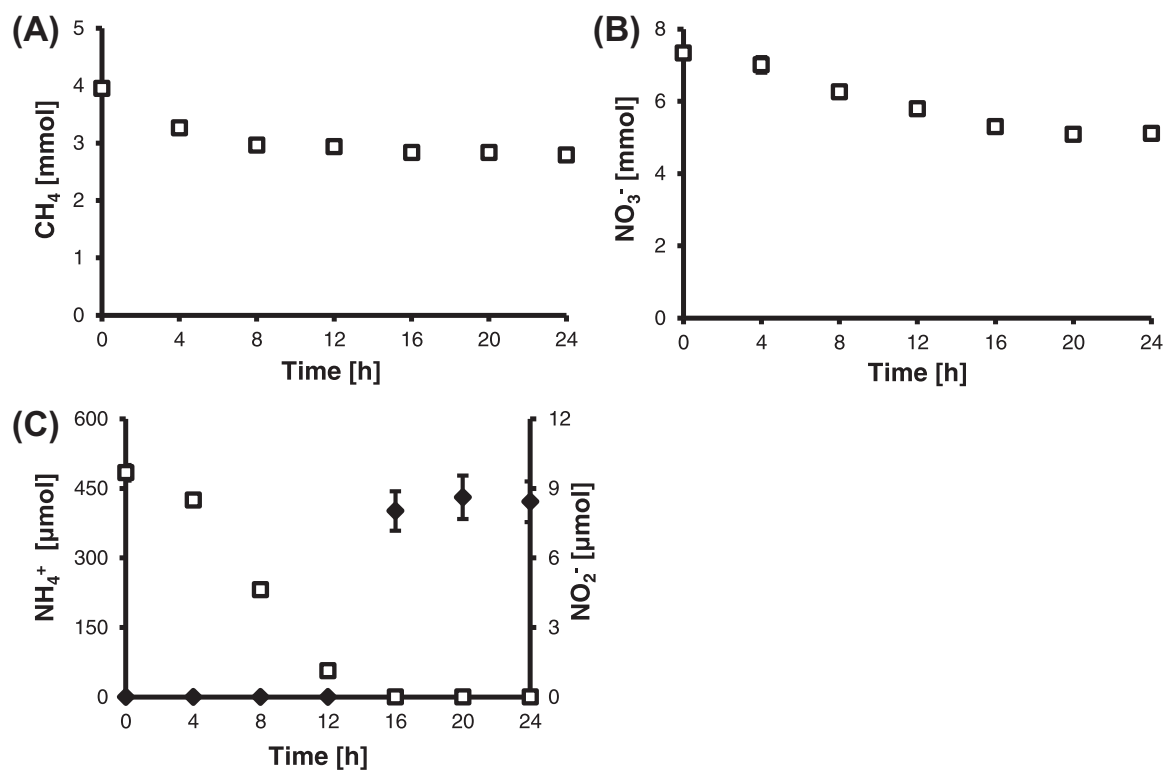

Fig. 1. Whole reactor batch activity assay. A. Methane oxidation recorded over a period of $24 \mathrm{~h}$.

B. Consumption of nitrate during the batch experiment.

C. Anammox activity established through consumption of ammonium and nitrite. The samples were collected every $4 \mathrm{~h}$ and measured in triplicates. Error bars represent standard deviation. The error bars in (A) and (B) are masked by the size of the data point. 

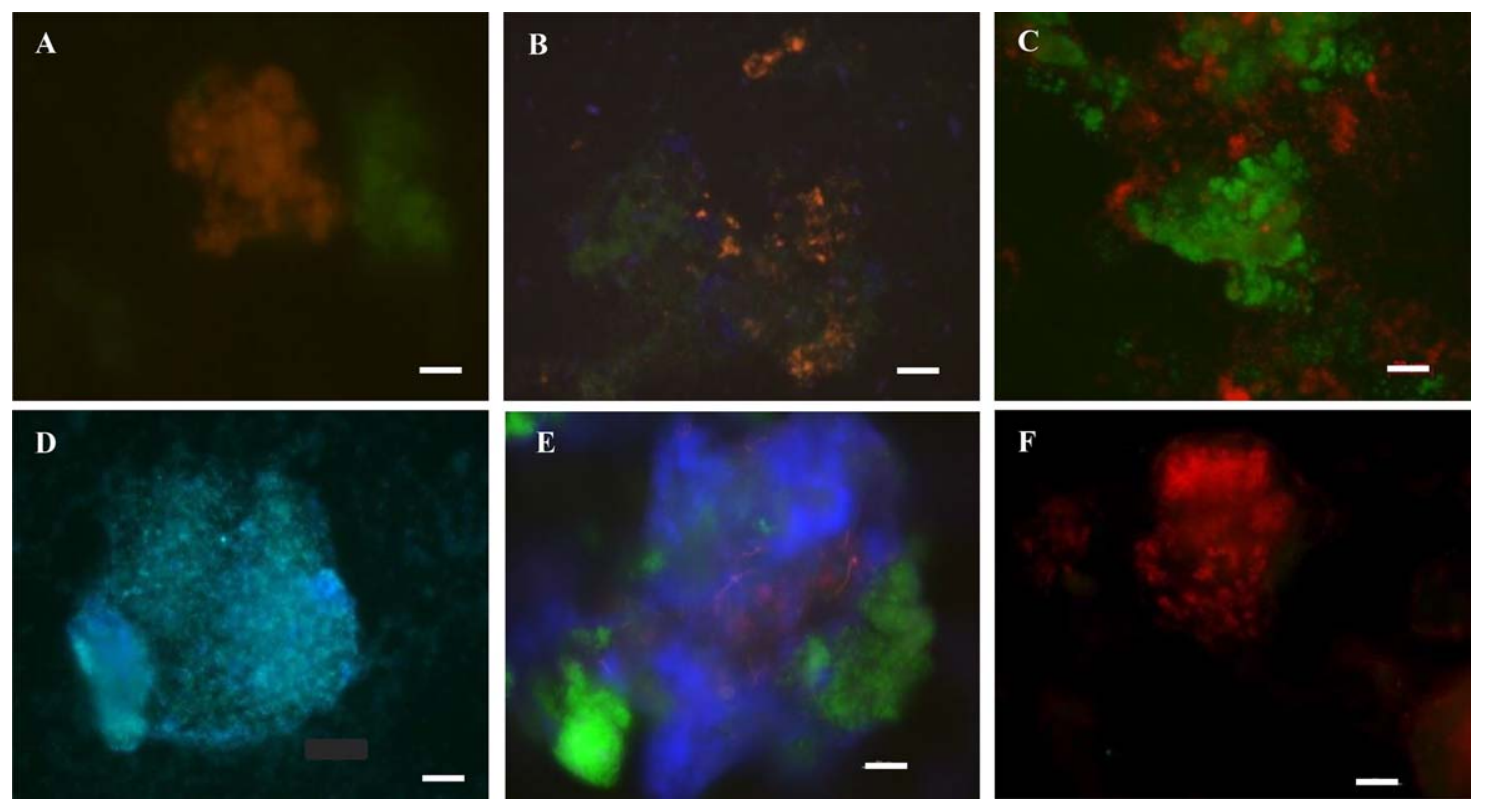

Fig. 2. Fluorescence in situ hybridization micrographs of the reactor biomass after 63 days (A and $B)$ and 258 days (C-F).

A. Candidatus M. nitroreducens visible in red (D-arch641-Cy3) and Ca. M. oxyfera in green (D-bact193-FLUOS).

B. Anammox bacteria visible in blue (Amx0820-Cy5), Sedimenticola sp. in green (GAM781-FLUOS) and Ca. M. oxyfera in red

(D-bact193-Cy3).

C. Candidatus M. nitroreducens visible in green (D-arch641-FLUOS) and Ca. M. oxyfera in red (D-bact193-Cy3).

D. Thiobacillus spp. visible in green (Betthio1001-FLUOS) and general bacteria visible in blue (Eub338 I-III-Cy5).

E. Betaproteobacteria visible in red (Bet42-Cy3), Ca. M. nitroreducens in green (D-arch641-FLUOS) and most bacteria labelled blue (Eub338 I-III-Cy5).

F. Anammox sp. visible in red (AMX368-Cy3). The scale bar represents $20 \mu \mathrm{m}$.

5'-phosphate (APS) by APS reductase (Apr) and eventually to sulfate by $5^{\prime}$-triphosphate sulfurylase (Sat). The genome also encoded the Sox enzyme system used for thiosulfate oxidation. Furthermore, genes encoding a complete denitrification pathway were present (Supporting Information Table S3). Interestingly, a membrane bound NarGHI nitrate reductase most closely related to Thiohalomonas sp., Thiohalomonas denitrificans and Methylotenera mobilis, respectively, in addition to a periplasmic NapAB related to that from S. denitricans sKB26 and Aspergillus oryzae, respectively, were identified. A cytochrome $c d_{1}$ nitrite reductase (NirS) and nitrous oxide reductase (NosZ), along with the nitric oxide reductase NorBC, were also detected. Furthermore, this bin encoded the ammonium-forming nitrite reductase NirBD, which was most closely related to the corresponding subunits in Thiobacillus sp. and Thauera phenylacetica. In addition to that, we recovered a high quality genome bin ( $98.8 \%$ complete with $0.73 \%$ contamination) phylogenetically placed within the Xanthomonadaceae family (93\% RpsC amino acid sequence similarity to Dyella koreensis). This organism was the third most abundant phylotype in the bioreactor ( $8.85 \%$ of the reads) and was likely involved in nitrogen cycling given the anoxic conditions in the bioreactor. An incomplete denitrification pathway to $\mathrm{N}_{2} \mathrm{O}$ was identified based on the presence of a nitrate transporter, narGHI, nirKS and norBC. We hypothesize that this organism may be involved in sulfide oxidation based on the presence of genes encoding a sulfide quinone oxidoreductase and two rhodanese-related sulfur transferases. No sulfur oxygenase reductase, ferredoxins, soluble HdrABCtype heterodisulfide reductases or molybdopterin oxidoreductases were encoded so it is unclear what the final product of sulfide oxidation may be. Under oxic condition, this microorganism might use aerobic respiration as the draft genome encoded the aerobic electron transport chain including NADH dehydrogenase (nuoA- $M$ ), succinate dehydrogenase ( $s d h A B C D$ ), cytochrome $b c_{1}$ complex (ISP, cyt $b$ and cyt $c_{1}$ ) and both $a a_{3}$ - and $c b b_{3}$-type cytochrome $c$ oxidases (CyOE and $\operatorname{COx} A B C D$ and subunits I, II, III and IV respectively). All genes in the central carbon metabolism for glycolysis, Entner-Doudoroff pathway, pentose phosphate pathway, citrate cycle and glyoxylate shunt were identified.

The most abundant community member in the bioreactor was a metabolically versatile novel species representing a new family within the Nitrospirae

Surprisingly, the most abundant taxonomic group according to the metagenome data was related to previously uncultured microorganisms within the Nitrospirae distantly 

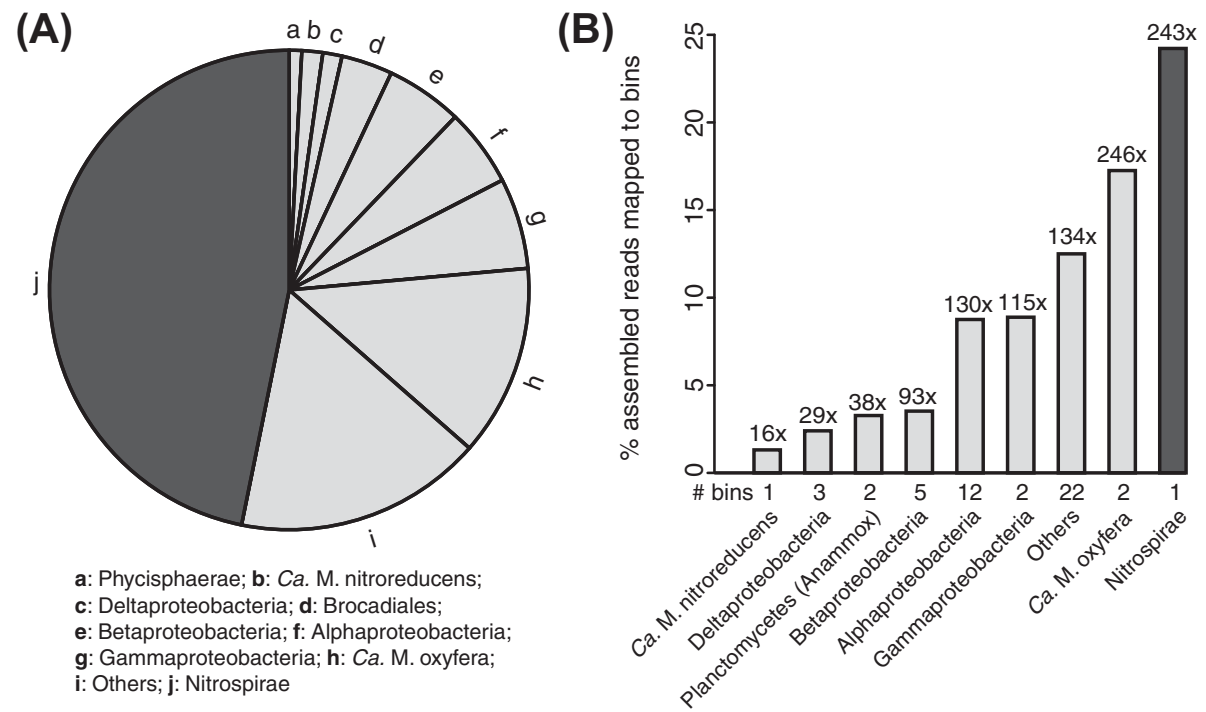

Fig. 3. Metagenome analysis of the bioreactor after 258 days.

A. Percent of metagenome reads that mapped to $16 \mathrm{~S}$ rRNA genes. (a-d) $16 \mathrm{~S}$ rRNA gene reads belonging to Phycisphaerae, Ca. M. nitroreducens, Deltaproteobacteria and Brocadiales were $1 \%, 2 \%, 2 \%$ and $4 \%$ respectively. (e-g) 16S rRNA reads associated with moderately abundant bacteria corresponded to Alphaproteobacteria (6\%), Betaproteobacteria (6\%) and Gammaproteobacteria (7\%). (h) A total of $16 \%$ of the reads matched the Ca. M. oxyfera 16S rRNA, the second most abundant microorganism. (i) A total of $17 \%$ of the $16 \mathrm{~S}$ rRNA reads belonged to the microorganisms related to Bacteroidetes, Acidobacteria, Chloroflexi and Gemmatimonadetes. (j) 16S rRNA reads belonging to class Nitrospirae.

B. Microbial abundances based on percent of mapped metagenome reads highlights the enrichment of a new Nitrospirae organism (darker grey in contrast with others in light grey). Percent of metagenome reads (assembled into contigs) that mapped to reconstructed microbial genomes (bins) are shown. While $83.1 \%$ of reads mapped to bins, $16.9 \%$ of the reads mapped to unbinned contigs. The number of bins ("\# bins") in each category is indicated at the $x$-axis, while coverage (" $x$ "), combined for each category, is displayed on top of each bar.

related to Thermodesulfovibrio sp. A high quality draft genome was obtained for this species through metagenome binning (100\% complete, predicted contamination level of $4.98 \%$ based on a single-copy maker gene analysis (Parks et al., 2015)). Total genome coverage was $242 x$, amounting to $24 \%$ of total binned reads in the bioreactor metagenome. The genome contained some common features with Thermodesulfovibrio $\mathrm{sp}$. (potential for sulfate reduction, electron donors hydrogen, formate and acetate) but also harbored new metabolic capabilities indicating a more versatile lifestyle than cultured Thermodesulfovibrio sp. and other Nitrospirae (Fig. 4 and Supporting Information Table S4). We found that the genome encoded a full sulfate reduction pathway (Sat, AprAB, reductive DsrAB) as well as an enzyme system catalysing DNRA (NirBD, $\mathrm{NrfH}$ ) and a complete aerobic respiratory chain (NADH dehydrogenase, succinate dehydrogenase, cytochrome $b c_{1}$ complex, cytochrome $a a_{3}$ oxidase). Partial denitrification was also encoded (nitrate permease, NarGHI, NapAB, NorBC). Divergent NirK/NirS might be present: two ORFs (Node 192, gene 26 and Node 268, gene 29) were $\sim 24-28 \%$ identical in amino acid sequence to reference NirK/NirS sequences. It has been suggested previously that divergent NirK proteins sharing only $10 \%$ sequence identity with reference proteins might still reduce nitrite to nitric oxide (Helen et al., 2016). However, experimental data are needed to confirm this hypothesis. Furthermore, the genome encoded the anaerobic respiratory enzymes trimethylamine $\mathrm{N}$-oxide (TMAO) and dimethylsulfoxide (DMSO) reductase. As electron donors, the small organic acids acetate (presence of genes encoding acetyl-CoA synthetase), formate (genes encoding formate dehydrogenase FdoG/FdfH), pyruvate (seven copies of pyruvate water dikinase and pyruvate: ferredoxin oxidoreductase) and lactate (lactate dehydrogenase) might be used. We also identified 5 alcohol dehydrogenases and an aldehyde: ferredoxin oxidoreductase. Several hydrogenase gene clusters (hyf and hyb, including maturation system hyp) suggest the possibility of hydrogen uptake or production. We did not find any indication for butyrate and propionate oxidation. Furthermore, we detected the genomic potential that these novel Nitrospirae bacteria are able to use simple carbohydrates based on a complete glycolysis pathway with the exception of aldolase, as well as a complete pentose phosphate pathway. Other potential electron donors are methyl groups. We found several subunits of different methyl transferases for methanol, mono-, di- and trimethyl amine related to enzymes found in sulfate reducers, acetogens and methanogens. Even though neither methanol or methylamine dehydrogenases nor a complete methyl 


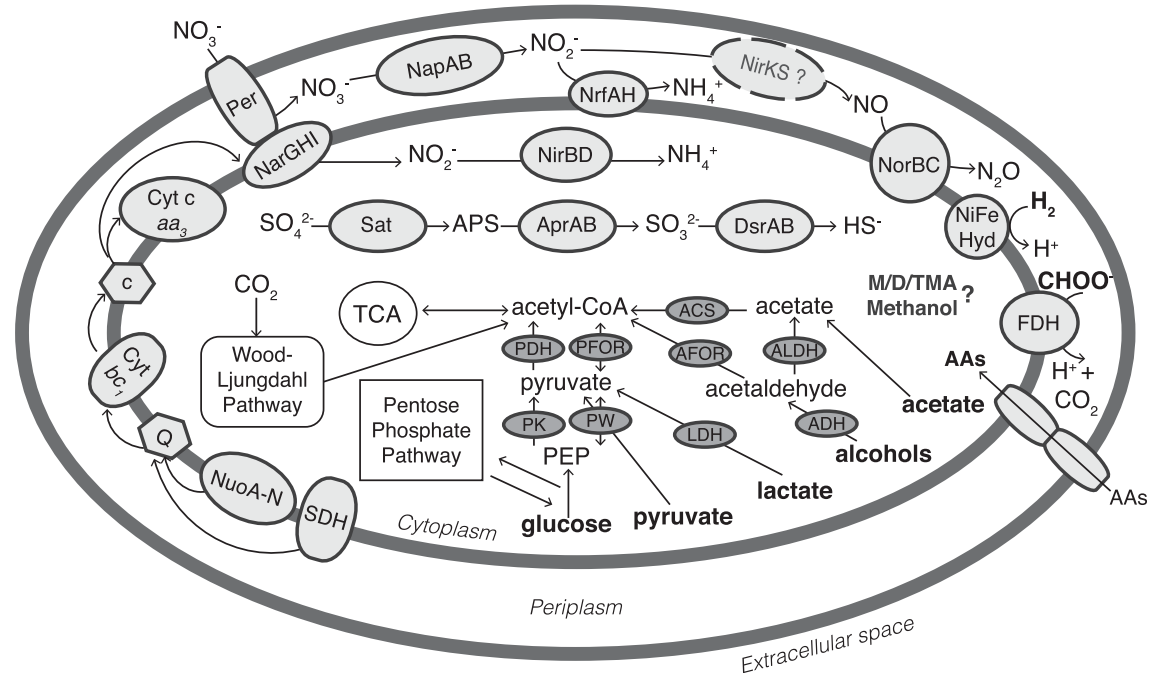

Fig. 4. Metabolic reconstruction of Nitrospirae phylum related bacteria based on a genome obtained from metagenomics data.

The main respiratory and central carbon metabolism pathways are represented with focus on potential electron donors and acceptors. We have identified the electron transport chain for oxygen ( $\mathrm{SDH}$ : succinate dehydrogenase/fumarate reductase; NuoA-N: NADH dehydrogenase; Q: quinone [quinone biosynthesis pathway]; Cyt $b c_{1}$ : Complex III; C: cytochrome $c$; Cyt $c$; aa $a_{3}$ : aa $a_{3}$-type terminal oxidase), nitrate (Per: nitrate permease; NarGHI: membrane-bound nitrate reductase; NirBD: cytoplasmic ammonium-forming nitrite reductase; NapAB: periplasmic nitrate reductase; NrfAH: membrane-bound ammonium-forming nitrite-reductase; NirKS: nitric oxide-forming nitrite reductase; NorBC: nitric oxide reductase) and sulfate [Sat: sulfate adenylyltransferase; AprAB: adenosine 5'-phosphosulfate (APS) reductase; DsrAB: dissimilatory sulfite reductase]. Candidate electron donors (printed in bold) include hydrogen, formate, acetate, alcohols, lactate, pyruvate and glucose. AAs: amino acids; ACS: acetyl-coenzyme A synthetase; ADH: alcohol dehydrogenase; AFOR: aldehyde:ferredoxin oxidoreductase; ALDH: aldehyde dehydrogenase; FDH: formate dehydrogenase; LDH: lactate dehydrogenase; M/D/TMA: mono-, di- and trimethylamines; NiFe Hyd: nickel-iron hydrogenases; PDH: pyruvate dehydrogenase; PEP: phosphoenolpyruvate; PFOR: pyruvate:ferredoxin oxidoreductase; PK: pyruvate phosphate dikinase; PW: pyruvate water dikinase; TCA: tricarboxylic acid cycle.

transferase operon was found, the abundance of individual subunits implicated in a methylotrophic lifestyle indicates that potentially methyl groups may be used as electron donors. The genome also encoded an (incomplete) tricarboxylic acid (TCA) cycle missing only the succinyl-CoA synthetase. No evidence was found for a reductive TCA cycle (no ATP-citrate lyase). Unlike Thermodesulfovibrio $\mathrm{sp}$., the here presented draft genome encoded a complete Wood-Ljungdahl pathway for autotrophic carbon fixation.

\section{Discussion}

\section{Competition and collaboration in the bioreactor reveal several major players in substrate turnover}

Competition for substrates and collaboration for providing intermediates or removal of toxic substances are key drivers for the shaping of microbial communities. We investigated the community dynamics and physiological activity of a microbial community under brackish conditions (1\% $\mathrm{NaCl}$ ) enriched in a laboratory-scale bioreactor supplied with mineral medium and nitrate, sulfide, ammonium and methane. After 1 year of operation, a stable microbial community in the bioreactor metabolized all substrates and it was possible to attribute tentative removal rates to different physiological groups (Supporting Information Fig. S1). Nitrogen loss in the form of $\mathrm{N}_{2}$ was due to the activity of anammox bacteria (Eq. 1), sulfide-dependent denitrifiers (Eq. 2) and the combined activity of nitrate- and nitritedependent anaerobic methanotrophs (Eq. 3):

$$
\begin{aligned}
& 1 \mathrm{NH}_{4}^{+}+1.32 \mathrm{NO}_{2}^{-} \rightarrow 1.02 \mathrm{~N}_{2}+0.26 \mathrm{NO}_{3}^{-}+2 \mathrm{H}_{2} \mathrm{O} \\
& 5 \mathrm{HS}^{-}+8 \mathrm{NO}_{3}^{-}+3 \mathrm{H}^{+} \rightarrow 5 \mathrm{SO}_{4}^{2-}+4 \mathrm{~N}_{2}+4 \mathrm{H}_{2} \mathrm{O} \\
& 5 \mathrm{CH}_{4}+8 \mathrm{NO}_{3}^{-}+8 \mathrm{H}^{+} \rightarrow 4 \mathrm{~N}_{2}+5 \mathrm{CO}_{2}+14 \mathrm{H}_{2} \mathrm{O}
\end{aligned}
$$

Metagenome sequencing indicated that, about 27\% from the total anammox-associated reads belonged to $\mathrm{Ca}$. K. stuttgartiensis while remaining $73 \%$ could be recovered in the genome bin belonging to $\mathrm{Ca}$. S. brodae. Anammox bacteria produced $1.22 \mathrm{mmol} \mathrm{N}_{2}$ and the nitrite-dependent methanotrophs $0.86 \mathrm{mmol}$. For the sulfide-dependent denitrifiers, a maximal amount of $0.23 \mathrm{mmol} \mathrm{N}_{2}$ could be produced if all nitrate was reduced to $\mathrm{N}_{2}$; probably some nitrate was reduced to nitrite (or ammonium) thus diminishing the amount of $\mathrm{N}_{2}$ emitted by this physiological group. In total, this would amount to a maximum total nitrogen loss of $2.31 \mathrm{mmol} \mathrm{N}_{2}$, of which $53 \%$ were produced by anammox bacteria. The nitrite-dependent methane oxidizers $\mathrm{Ca}$. M. oxyfera contributed to $37 \%$ of the total nitrogen loss, whereas the sulfide-dependent denitrifiers only contributed to about $10 \%$ of the nitrogen loss if all nitrate was reduced to $\mathrm{N}_{2}$. A previous study investigating the nitrogen loss in a 
bioreactor model that did not contain methane concluded that anammox accounted for $65-75 \%$ and sulfidedependent denitrifiers for $25-35 \%$ of the nitrogen loss (Russ et al., 2014). Our results clearly demonstrate that when methane is included as electron donor, methanedependent denitrifiers are competitive and will start to contribute substantially to the overall nitrogen loss. Although the sulfide-dependent denitrifiers only cause a maximum of $10 \%$ of the $\mathrm{N}_{2}$ loss, they contribute significantly $(31 \%)$ in providing nitrite for anammox bacteria and nitritedependent methanotrophs $\mathrm{Ca}$. M. oxyfera. The remaining $69 \%$ of nitrite is produced by the nitrate-dependent methanotrophs $\mathrm{Ca}$. M. nitroreducens. Methane was oxidized to almost equal parts by $\mathrm{Ca}$. M. oxyfera $(53 \%)$ and $\mathrm{Ca}$. M. nitroreducens $(47 \%)$ as was evident from the methane oxidation rates under sulfide depletion in the batch reactor assays. Under these conditions, nitrate is reduced to nitrite exclusively by $\mathrm{Ca}$. M. nitroreducens with stoichiometric methane oxidation according to the following equation:

$\mathrm{CH}_{4}+4 \mathrm{NO}_{3}^{-} \rightarrow \mathrm{CO}_{2}+4 \mathrm{NO}_{2}^{-}+2 \mathrm{H}_{2} \mathrm{O}$

Candidatus M. oxyfera is responsible for the remainder of the methane oxidation rate and nitrite reduction to $\mathrm{N}_{2}$ according to the following equation:

$3 \mathrm{CH}_{4}+8 \mathrm{NO}_{2}^{-}+8 \mathrm{H}^{+} \rightarrow 3 \mathrm{CO}_{2}+4 \mathrm{~N}_{2}+10 \mathrm{H}_{2} \mathrm{O}$

Besides competition and collaboration for substrates, the microbial community in the bioreactor was dependent on the removal of intermediates that could have a toxic effect. It has been noted previously that anammox bacteria are sensitive to sulfide stress (Russ et al., 2014) with a low $\mathrm{IC}_{50}$ of $10 \mu \mathrm{M}$. Therefore, anammox bacteria are dependent on the activity of sulfide-oxidizing microorganisms to keep the sulfide concentration below $1 \mu \mathrm{M}$. On the other hand, it seemed that sulfide stimulated the growth of $\mathrm{Ca}$. M. nitroreducens, presumably through the maintenance of a low redox potential and strictly anoxic conditions, as these methanotrophs rely on enzymes that are readily inactivated by oxygen.

First enrichment of novel Nitrospirae bacteria distantly related to Thermodesulfovibrio that are frequently found in environments with sulfur, nitrogen and methane cycling

The most abundant microorganism according to metagenome sequencing in the present study was organisms only distantly related to Thermodesulfovibrio $(87-89 \% 16 \mathrm{~S}$ rRNA gene identity) as the closest isolated representative and constituted about $24 \%$ of the microbial community based on the number of reads mapped to the draft genome. The metabolic reconstruction of this genome revealed the genomic potential for the use of a wide range of electron donors, i.e., hydrogen, pyruvate, lactate, acetate and formate, as well as a complete pathway for oxygen, nitrate, sulfate, DMSO and TMAO respiration. Also, it harbored a complete Wood-Ljungdahl pathway for autotrophic $\mathrm{CO}_{2}$ fixation or acetate oxidation. This microorganism can therefore be viewed as versatile and probably facultative anaerobic, capable of either an organoheterotrophic or chemolithoautotrophic lifestyle. In the current bioreactor system, only ammonium, sulfide and methane were provided as electron donors. The Nitrospirae related genome encodes neither ammonium nor methane activating enzymes indicating that it probably does not metabolize these substrates. Sulfide might be used by the reverse reaction of the sulfate reduction pathway; however, when we analyzed the phylogenetic relationship of the relevant DsrA protein encoded by these organisms, we noted that it falls into the sulfate-reducing and not the sulfideoxidizing cluster, making it unlikely that these bacteria are able to oxidize sulfide with DsrAB. It has however recently been reported that a reductive-type DsrAB might be able to work in the oxidative direction (Thorup et al., 2017), but this result has not yet been biochemically validated. We did not find a sulfide quinone oxidoreductase that could complement this activity, making it unlikely that sulfide is used as an electron donor. It has recently been observed that sulfur oxidation or disproportionation can be coupled to DNRA (Mardanov et al., 2016; Slobodkina et al., 2017), but the genes involved are not yet clear. Provided that sulfur compounds more oxidized than sulfide are excreted by the proteobacterial sulfide oxidizers, these might be substrates for the Nitrospirae-related bacteria. Other compounds, e.g., hydrogen and methanol, may be intermediary products of methane oxidation that are potentially released into the medium, alongside electron donors that become available from the turnover of biomass. It is, however, difficult to imagine how leakage products could lead to such a high abundance of this taxonomic group in the bioreactor, even if DNA extraction biases are taken into consideration.

When we analyzed the nitrogen cycling metabolic potential of these bacteria, it was interesting to note that both redundancies and omissions in well-described pathways occurred. Nitrate could clearly be reduced to nitrite by either NarGHI or NapAB type nitrate reductases. We found NrfA which is the catalytically active subunit of the nitrite: ammonium oxidoreductase enabling DNRA, together with its membrane anchor $\mathrm{NrfH}$ (Simon et al., 2003). Interestingly, it was not clear if the genome lacked genes encoding the nitrite reductases NirS and NirK. The genome encoded a nitric oxide reductase (NorBC) for the reduction of $\mathrm{NO}$ to $\mathrm{N}_{2} \mathrm{O}$. The $\mathrm{NO}$ reductase encoded by nos $Z$ was missing in the genome. The presence of millimolar quantities of nitrate in the bioreactor makes it unlikely that sulfate 


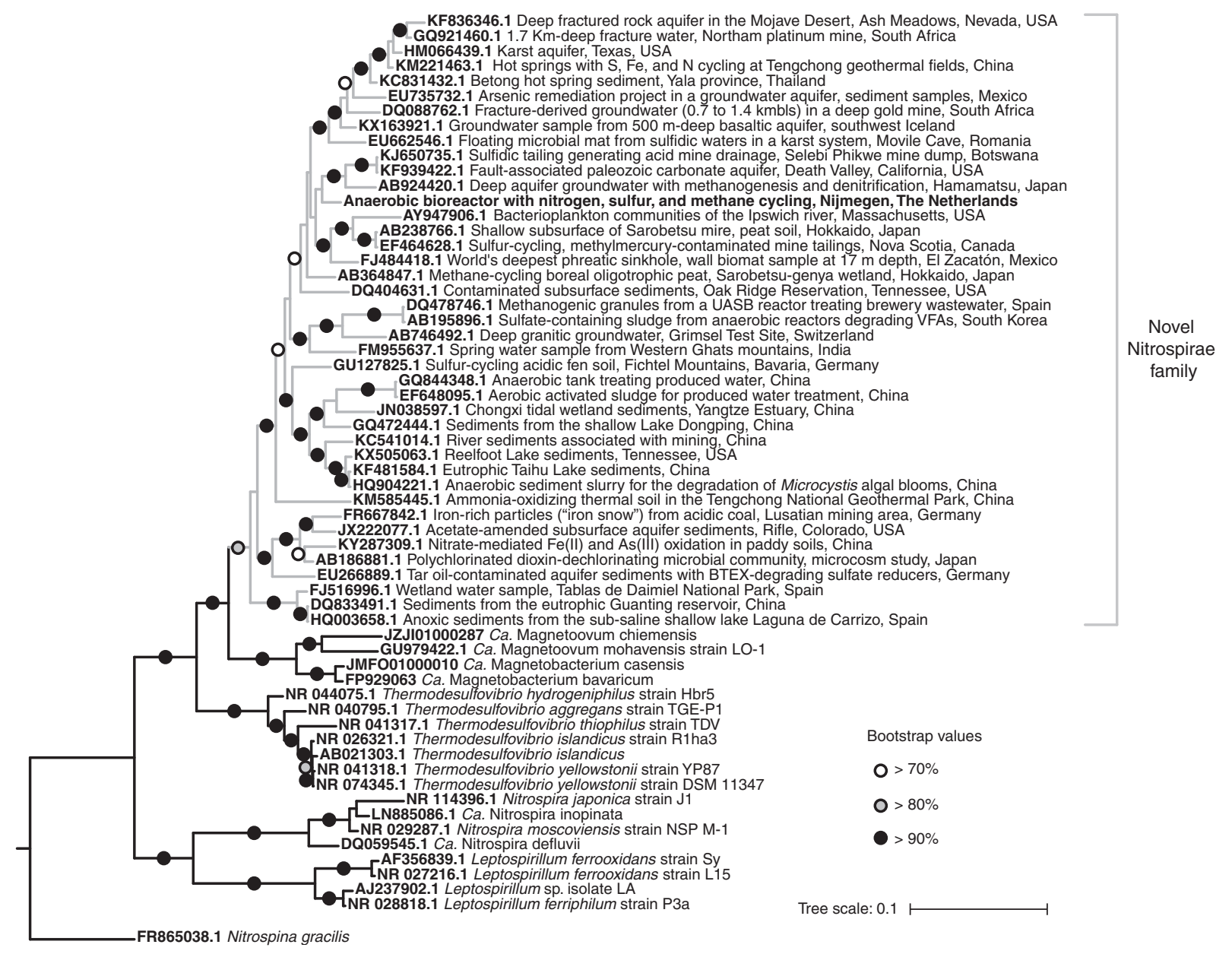

Fig. 5. Phylogenetic tree of sequences closely related to the novel Nitrospirae family bacterium enriched in this study.

The 100 best BLAST hits (nucleotide similarity $>90 \%$ ) to the 16S rRNA gene from the Nitrospirae family bacterium were retrieved. Representative sequences from 40 different studies were selected along with 20 isolate reference sequences from the NCBI and SILVA databases. All sequences affiliate within the phylum Nitrospirae, except the outgroup Nitrospina gracilis from the phylum Nitrospinae. The sequence similarity between the 16S rRNA gene of the novel Nitrospirae family bacterium and environmental sequences putatively clustering in a new family ranged from $91 \%$ to $95.5 \%$.

reduction was occurring, as nitrate respiration will thermodynamically outcompete sulfate respiration. However, it has been observed that microorganisms do not always abide to this rule (Dalsgaard and Bak, 1994; Canfield et al., 2010; Chen et al., 2017), and simultaneous nitrate and sulfate reduction cannot be excluded. In such a case, a cryptic sulfur cycle might be happening. Cryptic sulfur cycling has been previously found in marine oxygen minimum zones (Canfield et al., 2010) as well as terrestrial peat soils (Hausmann et al., 2016), freshwater sediments (Hansel et al., 2015) and sub-surface coal wells (Glombitza et al., 2016). Another possibility is that the Nitrospirae-related bacteria disproportionate sulfur compounds, eliminating the need for a designated electron donor. Unfortunately, the disproportionation of sulfur compounds is highly complex and not yet fully understood and the involved genes are unknown (Finster et al., 1998;
Frederiksen and Finster, 2003; Hardisty et al., 2013). Future research will target the isolation of these interesting microorganisms to study their physiology and possible role in the bioreactor.

Additionally, taxonomic groups related to the Nitrospirae bacteria found in this bioreactor occur in a wide range of environments that are implicated in sulfur, nitrogen and methane cycling. Thermodesulfovibrio spp. are the closest cultured representatives of the here presented bacterial group with 87-89\% rRNA gene identity (Fig. 5). The phylogenetic tree topology was corroborated by a phylogenetic tree of 17 concatenated ribosomal protein sequences (Supporting Information Fig. S2) and an average amino acid identity (AAI) value of 52-53\% (Supporting Information Table S5). Taking these values together, this novel Nitrospirae microorganism presumably belongs to a new family within the phylum Nitrospirae. We propose the 
following naming: Candidatus Nitrobium versatile gen. nov., sp. nov. Ni.tro'bi.um. L. n. nitrogenium nitrogen; Gr. n. bios life. neut. $n$. Nitrobium a living entity metabolizing nitrogen compounds. Candidatus N. versatile sp. nov. (ver.sa'ti.le L. adj. with a versatile metabolism). At the moment, all members of this phylum are classified as genera within the family Nitrospiraceae. Our data show that there are probably several distinct families to be defined within the family Nitrospiraceae. Therefore, the proposal of a new family within the phylum Nitrospirae would require a revision of the complete taxonomy within this order, even though our 16S rRNA gene identities and AAI values support the presence of a new family. A recent preprint article detected related microorganisms distantly related to Thermodesulfovibrio $\mathrm{sp}$. in rice paddy microcosms that were amended with gypsum $\left(\mathrm{CaSO}_{4} \cdot 2 \mathrm{H}_{2} \mathrm{O}\right)$ and based on a metagenomics assembled genome tentatively named Ca. Sulfobium mesophilum (Zecchin et al., 2017). As this genome sequence is not yet publically available the exact phylogenetic affiliation needs to be resolved in the future. We suggest to direct future efforts at resolving the taxonomic ambiguity within the phylum Nitrospirae.

Physiological characteristics of the closely related and cultured Thermodesulfovibrio spp. are the ability to perform dissimilatory sulfate, sulfite and thiosulfate reduction with a limited set up electron donors, i.e., hydrogen, formate, pyruvate and lactate (Henry et al., 1994; Haouari et al., 2008; Sekiguchi et al., 2008; Frank et al., 2016). All of the current isolated Thermodesulfovibrio sp. are thermophiles whereas the enriched Nitrospirae-related bacteria grew at ambient temperature. Konno and colleagues detected Thermodesulfovibrio-like sequences (91-92\% 16S rRNA gene identity) in freshwater aquifers in the terrestrial subsurface which is a very oligotrophic ecosystem (Konno et al., 2013). Lau and colleagues (2014) found Thermodesulfovibrio-like metagenome sequences in the South African continental crust under mesophilic conditions where biogeochemical cycling of nitrogen, sulfur and methane had been shown previously. Baker and colleagues (2015) investigated the genomic potential of a microbial community in estuary sediments. They were able to reconstruct environmental genomes harboring the potential to contribute to the carbon, nitrogen and sulfur cycle. One of their environmental genomes was distantly related to Thermodesulfovibrio. That genome harbored the metabolic potential for some fermentative pathways, hydrogen production or consumption and dissimilatory sulfate reduction. Interestingly, a recent amplicon sequencing survey of river sediments impacted by freshwater mussels discovered the co-occurrence of anammox bacteria, nitrate- and nitritedependent methanotrophs as well as Thermodesulfovibriolike sequences (Black et al., 2017). Their survey did not target sulfide-dependent denitrifiers, but proteobacteria were abundantly present and could potentially be involved in nitrate-dependent sulfide oxidation. Especially these two studies by Baker and colleagues $(2015 ; 2017)$ describe ecosystems that mirror the enrichment conditions in the here presented bioreactor: the interlinkage of sulfur, nitrogen and methane cycling leading to the enrichment of known and new players in these processes.

Furthermore, we performed a database survey targeting environmental 16S rRNA gene sequences (Fig. 5) related to those found in our novel Nitrospirae family bacterial genome. We found sequences that shared $91-95.5 \%$ identity to the one identified here in 40 different studies. Most notably, half of them originated from freshwater sediments (wetlands, rivers, lakes, reservoirs) and soils (peat, fen, paddies). Interestingly, $21 \%$ of environmental sequences were recovered from bioreactors or sediment slurries for the degradation of diverse compounds, while $14 \%$ of these sequences derived from the deep terrestrial subsurface. The ubiquitous distribution of members in this new Nitrospirae family highlights the potential role of such organisms in the biogeochemical cycles in diverse environments relevant for methane, sulfur and nitrogen cycling.

\section{Experimental procedures}

\section{Enrichment and reactor operation}

A 2.5 I bioreactor (Applikon, Delft, The Netherlands) with a working volume of 1.5 I was used for cultivation of the enrichment culture for a period of 382 days. It was operated at room temperature. The inoculum consisted of biomass from a marine enrichment culture containing sulfide-dependent autotrophic denitrifiers and anammox bacteria (Russ et al., 2014) and biomass from a freshwater methane-oxidizing denitrification culture (Ettwig et al., 2016). The reactor was operated at $150 \mathrm{rpm}$ with a stirrer that contained two standard six-blade turbines. The flow of methane gas to the reactor was kept at $7.5 \mathrm{ml} \mathrm{min}{ }^{-1}$ using a mass flow controller (Brooks Instrument, Ede, The Netherlands). Additionally, the bioreactor was constantly flushed with $\mathrm{Ar} / \mathrm{CO}_{2}$ (95:5) to ensure anoxic conditions. The $\mathrm{pH}$ of the reactor liquid was monitored with a $\mathrm{pH}$ electrode (Applisens; Applikon, Delft, The Netherlands) and was maintained at 7.1 with $100 \mathrm{~g} \mathrm{I}^{-1} \mathrm{KHCO}_{3}$ solution. The $\mathrm{pH}$ pump was controlled by an ADI 1010 biocontroller (Applikon). The mineral medium per litre contained $10 \mathrm{~g}$ coral pro salt (Red Sea), $7 \mathrm{mM} \mathrm{NH}_{4} \mathrm{Cl}, 15 \mathrm{mM} \mathrm{NaNO}_{3}, 0.6 \mathrm{ml}$ anammox specific trace element solution (van de Graaf et al., 1996) (15 $\mathrm{g} \mathrm{I}^{-1}$ EDTA, $0.43 \mathrm{~g} \mathrm{I}^{-1} \mathrm{ZnSO}_{4} \cdot 7 \mathrm{H}_{2} \mathrm{O}, 0.24 \mathrm{~g} \mathrm{I}^{-1} \mathrm{CoCl}_{2} \cdot 6 \mathrm{H}_{2} \mathrm{O}$, $0.99 \mathrm{~g} \mathrm{I}^{-1} \mathrm{MnCl}_{2} \cdot 4 \mathrm{H}_{2} \mathrm{O}, 0.25 \mathrm{~g} \mathrm{I}^{-1} \mathrm{CuSO}_{4} \cdot 5 \mathrm{H}_{2} \mathrm{O}, 0.22 \mathrm{~g} \mathrm{I}^{-1}$ $\mathrm{Na}_{2} \mathrm{MoO}_{4} \cdot 2 \mathrm{H}_{2} \mathrm{O}, 0.2 \mathrm{~g} \mathrm{l}^{-1} \mathrm{NiCl}_{2} \cdot 6 \mathrm{H}_{2} \mathrm{O}, 0.067 \mathrm{~g} \mathrm{I}^{-1} \mathrm{SeO}_{2}$, $\left.0.014 \mathrm{~g} \mathrm{I}^{-1} \mathrm{H}_{3} \mathrm{BO}_{3}, 0.05 \mathrm{~g} \mathrm{I}^{-1} \mathrm{Na}_{2} \mathrm{WO}_{4} \cdot 2 \mathrm{H}_{2} \mathrm{O}\right), 0.6 \mathrm{ml} \mathrm{FeSO}$, $0.5 \mathrm{ml} 100 \mathrm{~g} \mathrm{~K}_{2} \mathrm{HPO}_{4}, 1.25 \mathrm{ml}\left(288 \mathrm{mg} \mathrm{l}^{-1}\right) \mathrm{MgSO}_{4}, 1.25 \mathrm{ml}$ (192 $\mathrm{mg} \mathrm{l}^{-1}$ ) $\mathrm{CaCl}_{2}$ and $1 \mathrm{ml}$ trace element solution for DAMO microorganisms $\left(0.5 \mathrm{~g} \mathrm{I}^{-1} \mathrm{ZnSO}_{4} \cdot 7 \mathrm{H}_{2} \mathrm{O}, 0.12 \mathrm{~g} \mathrm{I}^{-1}\right.$ $\mathrm{CoCl}_{2} \cdot 6 \mathrm{H}_{2} \mathrm{O}, 2 \mathrm{~g} \mathrm{I}^{-1} \mathrm{CuSO}_{4}, 0.2 \mathrm{~g} \mathrm{I}^{-1} \mathrm{NiCl}_{2} \cdot 6 \mathrm{H}_{2} \mathrm{O}, 0.014 \mathrm{~g} \mathrm{I}^{-1}$ $\mathrm{H}_{3} \mathrm{BO}_{3}, 0.3 \mathrm{~g} \mathrm{I}^{-1} \mathrm{MnCl}_{2} \cdot 4 \mathrm{H}_{2} \mathrm{O}, 0.04 \mathrm{~g} \mathrm{I}^{-1} \mathrm{Na}_{2} \mathrm{WO}_{4} \cdot 2 \mathrm{H}_{2} \mathrm{O}$, $0.2 \mathrm{~g} \mathrm{I}^{-1} \mathrm{Na}_{2} \mathrm{MoO}_{4} \cdot 2 \mathrm{H}_{2} \mathrm{O}, 0.02 \mathrm{~g} \mathrm{I}^{-1} \mathrm{SeO}_{2}, 0.8 \mathrm{~g} \mathrm{I}^{-1} \mathrm{CeCl}_{2}$ ). The $6.7 \mathrm{mM}$ sulfide solution was provided as separate anaerobic medium with a flow rate $100 \mathrm{ml}$ day ${ }^{-1}$. The nitrate and nitrite concentrations in the bioreactor were measured daily 
with MQuant ${ }^{\mathrm{TM}}$ colorimetric test strips (Merck, Darmstadt, Germany). Sulfide concentration was measured through acidification with $0.5 \mathrm{M} \mathrm{HCl}$ and injecting the gas samples to a gas chromatograph (7890B GC systems, Agilent Technologies, Santa Clara, CA). The GC was equipped with a Carbopak BHT-100 column (60-80 mesh) and flame photometric detector (FPD). The injection and detection temperature was $200^{\circ} \mathrm{C}$, and the oven temperature was $80^{\circ} \mathrm{C}$.

\section{Whole culture batch activity assays}

To measure methane consumption, medium and gas supplies were stopped and headspace methane concentration decreased to ca. $10 \%$ by flushing with $\mathrm{Ar} / \mathrm{CO}_{2}$ (95:5). The methane concentration was then measured every $4 \mathrm{~h}$ for a period of $2 \mathrm{~h}$. At each sampling time, headspace gas samples of $100 \mu$ were withdrawn with a gas tight glass syringe (Hamilton, Switzerland) and immediately measured through a HP 5890 gas chromatograph equipped with a Porapak Q column (80/100 mesh) and flame ionization detector (Hewlett Packard, Palo Alto, CA). The injection and detection temperature was $150^{\circ} \mathrm{C}$, and the oven temperature was $120^{\circ} \mathrm{C}$. Final methane concentrations were calculated through calibration gas and self-made standards. Additionally, $2 \mathrm{ml}$ liquid sample was centrifuged and supernatant stored at $-20^{\circ} \mathrm{C}$ for determination of nitrogenous compounds. Nitrite was measured colorimetrically at $540 \mathrm{~nm}$ after a 15 min-reaction of $1 \mathrm{ml} \mathrm{sam}$ ple $(0.05-0.5 \mathrm{mM}$ nitrite) with $1 \mathrm{ml} 1 \%$ sulfanilic acid in $1 \mathrm{M}$ $\mathrm{HCl}$ and $1 \mathrm{ml} 0.1 \%$ naphtylethylene diaminedihydrochloride (Griess, 1879). Ammonium was measured at $420 \mathrm{~nm}$ on a 96well fluorescence spectrophotometer after reaction with $10 \%$ ortho-phthaldialdehyde as described previously (Taylor et al., 1974). Nitrate was measured with a Sievers Nitric Oxide analyzer (NOA280i; GE Power Water \& Process Technologies, Boulder, CO). The sample measurements were carried out in duplicates.

\section{Metagenome sequencing and analysis}

On day 258, $150 \mathrm{ml}$ biomass for genomic DNA extraction was sampled from the bioreactor, homogenized in a glass homogenizer to disrupt granules, and DNA was extracted with two different extraction methods in triplicate, the FastDNA Spin Kit (MP Biomedicals, Santa Ana CA) and the cetyltrimethylammoniumbromide (CTAB) method (Zhou et al., 1996). DNA was quantified with the Qubit Fluorometer (Thermo Fisher Scientific, Waltham, MA). DNA (1 ng) from both extraction methods was used for MiSeq library preparation. The genomic DNA was sheared and adapters were ligated in the same step. The Illumina Nextera ${ }^{\circledR}$ XT Library Prep Kit was used according to the manufacturer's instructions (Illumina, San Diego, CA). The library was normalized to $4 \mathrm{nM}$ and sequencing was performed with an Illumina MiSeq (Illumina) using the 300 pairedend sequencing protocol. Quality-trimming, adapter removal and contaminant-filtering of paired-end sequencing reads was performed using BBDUK (BBTOOLS version 37.17) (Bushnell, 2015). The Fast Spin DNA extraction kit and CTAB method yielded 10.8 and 7.8 million trimmed reads $>150 \mathrm{bp}$ respectively. Reads obtained from both DNA extractions were co-assembled with metaSPAdes v3.10.1 (Nurk et al., 2017) using default settings. MetaSPAdes iteratively assembled the metagenome using kmer sizes 21, 33, 55, 77, 99 and 127. Reads were mapped back to the metagenome for each extraction separately using Burrows-Wheeler Aligner 0.7.15 (Li and Durbin, 2010) (BWA), employing the "mem" algorithm. The generated sequence mapping files were handled and converted as needed using SAMtools 2.1 (Li et al., 2009). Metagenome binning was performed employing five different binning algorithms: BinSanity v0.2.5.9 (Graham et al., 2017), COCACOLA (Lu et al., 2016), CONCOCT (Alneberg et al., 2014), MaxBin 2.0 2.2.3 (Wu et al., 2016) and MetaBAT 2 2.10.2 (Kang et al., 2015). The five resulting bin sets were supplied to DAS Tool 1.0 (C.M.K. Sieber, A.J. Probst, A. Sharrar, B.C. Thomas, M. Hess, S.G. Tringe and J.F. Banfield, unpublished) for consensus binning to obtain the final optimized bins. The quality of the consensus bins was assessed using CheckM 1.0.7 (Parks et al., 2015). From 18 million trimmed, quality controlled metagenome reads, 93.9\% were assembled into contigs, $82.8 \%$ mapped to contigs and $78 \%$ mapped to binned contigs. Genes were called and annotated as previously described by (Wrighton et al., 2012) with a pipeline available online (https://github.com/TheWrightonLab/ metagenome_annotation). Briefly, genes were called with Prodigal (Hyatt et al., 2010) and annotated based on forward and reverse blast hits to amino acid sequences in UniRef90 (http://www.uniprot.org/help/uniref) and KEGG (http://www. genome.jp/kegg/). Thresholds for reciprocal best blast matches were a minimum 300 bit score and, for one-way blast matches, a minimum 60 bit score. Motifs were also analysed using InterproScan. Complete or partial 16S rRNA genes in bins were identified with SSU-Align (Nawrocki, 2009). The 16S rRNA gene of the novel Nitrospirae phylum bacterium was completed by two cycles of stringent mapping and elongation of the contigs obtained after assembly of all 16S rRNA gene reads extracted from the metagenome. The metagenome data are available at NCBI under accession number (PRJNA397647). For the biogeography, the complete 16S rRNA gene in the Nitrospirae bin was blasted on NCBI (https://www.ncbi.nlm.nih.gov/). The first 100 best hits were further analysed for similarity, sample type and country of origin. For phylogenetic trees, sequences (nucleotide or amino acid, as indicated in each figure) were aligned with MUSCLE (Edgar, 2004). The biogeography 16S rRNA gene tree was built on an alignment containing 1,651 positions using FastTree (Price et al., 2010) with 100 bootstraps. For the concatenated ribosomal protein tree, 17 ribosomal proteins (L1, L2, L3, L4, L5, L6, L14, L15, L16, L19, L20, L24, S3, S8, S11, S13 and S19) were identified using hmmsearch (-E 0.00001) (Johnson et al., 2010) and independently aligned. Alignment columns with $95 \%$ gaps were stripped and then concatenated in Geneious v. 9.0.5 (Kearse et al., 2012), generating an alignment with 3,304 positions. This tree was built using RAxML v. 8.2.9 with 100 bootstraps under the LG model of evolution on a pipeline available online at https://github.com/TheWrightonLab/Protpipeliner as previously described (Solden et al., 2017). Trees were visualized with iToL (Letunic and Bork, 2016). Reference sequences in these trees were retrieved from NCBI or SILVA (https://www. arb-silva.de/). Plots were made in $\mathrm{R}$ ( $\mathrm{R}$ Development Core Team, 2017), and all figures were edited in Adobe Illustrator version 16.0.0 (Adobe Systems Inc., San Jose, CA). Average 
amino acid identity (AAI) values were calculated using the Kostas lab tool available at http://enve-omics.ce.gatech.edu/ g-matrix/.

\section{Fluorescence in situ hybridization (FISH)}

Biomass samples were taken after 63 and 258 days and prepared as previously described (Russ et al., 2014). FISH was performed as described by Amann et al. (1990) using a hybridization buffer containing either $30 \%$ or $20 \%$ ( vol $/ \mathrm{vol}$ ) formamide. Specifications and the details of the probes used in this study are provided in Supporting Information Table S1. For image acquisition, a Zeiss Axioplan 2 epifluorescence microscope equipped with a CCD camera was used together with the Axiovision software package (Zeiss, Oberkochen, Germany). Vectashield mounting fluid with DAPI (4,6-diamidino-2-phenylindole) was used on all samples to stain all DNA.

\section{Acknowledgements}

The authors are thankful to Kelly Wrighton, Michael Wilkins and Sebastian Lücker for metagenomics and bioinformatics support, as well as Theo van Alen for technical assistance. Furthermore, financial support from the Nederlandse Organisatie voor Wetenschappelijk Onderzoek through the SIAM Gravitation Grant 024.002.002 and the NESSC Gravitation Grant 024.002.001 is thankfully acknowledged. MSMJ and AA were supported by the ERC AG EcoMoM 339880. HOdC was supported by ERC AG Volcano 669371. The funding agencies had no role in study design, data collection and interpretation, or the decision to submit the work for publication.

\section{References}

Alneberg, J., Bjarnason, B.S., de Bruijn, I., Schirmer, M., Quick, J., ljaz, U.Z., et al. (2014) Binning metagenomic contigs by coverage and composition. Nat Methods 11: 1144-1146.

Amann, R.I., Binder, B.J., Olson, R.J., Chisholm, S.W., Devereux, R., and Stahl, D.A. (1990) Combination of $16 S$ rRNA-targeted oligonucleotide probes with flow cytometry for analyzing mixed microbial populations. Appl Environ Microbiol 56: 1919-1925.

Arshad, A., Speth, D.R., de Graaf, R.M., Op den Camp, H.J.M., Jetten, M.S.M., and Welte, C.U. (2015) A metagenomics-based metabolic model of nitrate-dependent anaerobic oxidation of methane by Methanoperedens-like archaea. Front Microbiol 6: 1423.

Baker, B.J., Lazar, C.S., Teske, A.P., and Dick, G.J. (2015) Genomic resolution of linkages in carbon, nitrogen, and sulfur cycling among widespread estuary sediment bacteria. Microbiome 3: 14.

van den Berg, E.M., van Dongen, U., Abbas, B., and van Loosdrecht, M.C. (2015) Enrichment of DNRA bacteria in a continuous culture. ISME J 9: 2153-2161.

Black, E.M., Chimenti, M.S., and Just, C.L. (2017) Effect of freshwater mussels on the vertical distribution of anaerobic ammonia oxidizers and other nitrogen-transforming microorganisms in upper Mississippi river sediment. PeerJ 5: e3536.
Bushnell, B. (2015) BBMap - Bushnell B. URL sourceforge. net/projects/bbmap/.

Canfield, D.E., Glazer, A.N., and Falkowski, P.G. (2010) The evolution and future of earth's nitrogen cycle. Science 330 : 192-196.

Canfield, D.E., Stewart, F.J., Thamdrup, B., De Brabandere, L., Dalsgaard, T., Delong, E.F., et al. (2010) A cryptic sulfur cycle in oxygen-minimum-zone waters off the Chilean coast. Science 330: 1375-1378.

Chen, J., Hanke, A., Tegetmeyer, H.E., Kattelmann, I., Sharma, R., Hamann, E., et al. (2017) Impacts of chemical gradients on microbial community structure. ISME $J 11$ : 920-931.

Dalsgaard, F., and Bak, T. (1994) Nitrate reduction in a sulfate-reducing bacterium, Desulfovibrio desulfuricans, isolated from rice paddy soil. Appl Environ Microbiol 60: 291-297.

Dong, L.F., Thornton, D.C.O., Nedwell, D.B., and Underwood, G.J.C. (2000) Denitrification in sediments of the river Colne Estuary, England. Mar Ecol Prog Ser 203: 109-122.

Edgar, R.C. (2004) MUSCLE: multiple sequence alignment with high accuracy and high throughput. Nucleic Acids Res 32: 1792-1797.

Egger, M., Rasigraf, O., Sapart, C.J., Jilbert, T., Jetten, M.S.M., Röckmann, T., et al. (2015) Iron-mediated anaerobic oxidation of methane in brackish coastal sediments. Environ Sci Technol 49: 277-283.

Ettwig, K.F., Butler, M.K., Le Paslier, D., Pelletier, E., Mangenot, S., Kuypers, M.M.M., et al. (2010) Nitrite-driven anaerobic methane oxidation by oxygenic bacteria. Nature 464: 543-548.

Ettwig, K.F., Zhu, B., Speth, D., Keltjens, J.T., Jetten, M.S.M., and Kartal, B. (2016) Archaea catalyze iron-dependent anaerobic oxidation of methane. Proc Natl Acad Sci USA 113: 12792-12796.

Falkowski, P.G., Fenchel, T., and Delong, E.F. (2008) The microbial engines that drive earth's biogeochemical cycles. Science 320: 1034-1039.

Finster, K., Liesack, W., and Thamdrup, B. (1998) Elemental sulfur and thiosulfate disproportionation by Desulfocapsa sulfoexigens sp. nov., a new anaerobic bacterium isolated from marine surface sediment. Appl Environ Microbiol 64: 119-125.

Frank, Y.A., Kadnikov, V.V., Lukina, A.P., Banks, D., Beletsky, A.V., Mardanov, A.V., et al. (2016) Characterization and genome analysis of the first facultatively alkaliphilic Thermodesulfovibrio isolated from the deep terrestrial subsurface. Front Microbiol 7: 2000.

Frederiksen, T.-M., and Finster, K. (2003) Sulfite-oxidoreductase is involved in the oxidation of sulfite in Desulfocapsa sulfoexigens during disproportionation of thiosulfate and elemental sulfur. Biodegradation 14: 189-198.

Glombitza, C., Adhikari, R.R., Riedinger, N., Gilhooly, W.P., Hinrichs, K.-U., and Inagaki, F. (2016) Microbial sulfate reduction potential in coal-bearing sediments down to $\sim 2.5 \mathrm{~km}$ below the seafloor off Shimokita Peninsula, Japan. Front Microbiol 7: 1576.

van de Graaf, A.A., de Bruijn, P., Robertson, L.A., Jetten, M.S.M., and Kuenen, J.G. (1996) Autotrophic growth of anaerobic ammonium-oxidizing micro-organisms in a fluidized bed reactor. Microbiology 142: 2187-2196. 
Graham, E.D., Heidelberg, J.F., and Tully, B.J. (2017) BinSanity: unsupervised clustering of environmental microbial assemblies using coverage and affinity propagation. PeerJ 5: e3035.

Griess, P. (1879) Bemerkungen zu der Abhandlung der $\mathrm{HH}$. Weselsky und Benedikt "Ueber einige Azoverbindungen". Ber Dtsch Chem Ges 12: 426-428.

Hansel, C.M., Lentini, C.J., Tang, Y., Johnston, D.T., Wankel, S.D., and Jardine, P.M. (2015) Dominance of sulfur-fueled iron oxide reduction in low-sulfate freshwater sediments. ISME J 9: 2400-2412.

Haouari, O., Fardeau, M.-L., Cayol, J.-L., Casiot, C., ElbazPoulichet, F., Hamdi, M., et al. (2008) Desulfotomaculum hydrothermale sp. nov., a thermophilic sulfate-reducing bacterium isolated from a terrestrial Tunisian hot spring. Int $J$ Syst Evol Microbiol 58: 2529-2535.

Hardisty, D.S., Olyphant, G.A., Bell, J.B., Johnson, A.P., and Pratt, L.M. (2013) Acidophilic sulfur disproportionation. Geochim Cosmochim Acta 113: 136-151.

Haroon, M.F., Hu, S., Shi, Y., Imelfort, M., Keller, J., Hugenholtz, P., et al. (2013) Anaerobic oxidation of methane coupled to nitrate reduction in a novel archaeal lineage. Nature 500: 567-570.

Hausmann, B., Knorr, K.-H., Schreck, K., Tringe, S.G., Glavina del Rio, T., Loy, A., et al. (2016) Consortia of lowabundance bacteria drive sulfate reduction-dependent degradation of fermentation products in peat soil microcosms. ISME J 10: 2365-2375.

Helen, D., Kim, H., Tytgat, B., and Anne, W. (2016) Highly diverse nirk genes comprise two major clades that harbour ammonium-producing denitrifiers. BMC Genomics 17: 155.

Henry, E.A., Devereux, R., Maki, J.S., Gilmour, C.C., Woese, C.R., Mandelco, L., et al. (1994) Characterization of a new thermophilic sulfate-reducing bacterium. Arch Microbiol 161: 62-69.

Hyatt, D., Chen, G.-L., LoCascio, P.F., Land, M.L., Larimer, F.W., and Hauser, L.J. (2010) Prodigal: prokaryotic gene recognition and translation initiation site identification. BMC Bioinformatics 11: 119.

Johnson, L.S., Eddy, S.R., and Portugaly, E. (2010) Hidden Markov model speed heuristic and iterative HMM search procedure. BMC Bioinformatics 11: 431.

Kang, D.D., Froula, J., Egan, R., and Wang, Z. (2015) MetaBAT, an efficient tool for accurately reconstructing single genomes from complex microbial communities. PeerJ 3: e1165.

Kearse, M., Moir, R., Wilson, A., Stones-Havas, S., Cheung, M., Sturrock, S., et al. (2012) Geneious Basic: an integrated and extendable desktop software platform for the organization and analysis of sequence data. Bioinformatics 28: 1647-1649.

Konno, U., Kouduka, M., Komatsu, D.D., Ishii, K., Fukuda, A., Tsunogai, U., et al. (2013) Novel microbial populations in deep granitic groundwater from grimsel test site, Switzerland. Microb Ecol 65: 626-637.

Kraft, B., Strous, M., and Tegetmeyer, H.E. (2011) Microbial nitrate respiration - genes, enzymes and environmental distribution. J Biotechnol 155: 104-117.

Lau, M.C.Y., Cameron, C., Magnabosco, C., Brown, C.T., Schilkey, F., Grim, S., et al. (2014) Phylogeny and phylogeography of functional genes shared among seven terrestrial subsurface metagenomes reveal $\mathrm{N}$-cycling and microbial evolutionary relationships. Front Microbiol 5: 531.

Letunic, I., and Bork, P. (2016) Interactive tree of life (iTOL) v3: an online tool for the display and annotation of phylogenetic and other trees. Nucleic Acids Res 44: W242-W245.

Li, H., and Durbin, R. (2010) Fast and accurate long-read alignment with Burrows-Wheeler transform. Bioinformatics 26: 589-595.

Li, H., Handsaker, B., Wysoker, A., Fennell, T., Ruan, J., Homer, N., et al. (2009) The sequence alignment/map format and SAMtools. Bioinformatics 25: 2078-2079.

Lu, Y.Y., Chen, T., Fuhrman, J.A., and Sun, F. (2016) COCACOLA: binning metagenomic contigs using sequence COmposition, read CoverAge, CO-alignment and paired-end read LinkAge. Bioinformatics 33: 791-798.

Luesken, F.A., Sanchez, J., van Alen, T.A., Sanabria, J., Op den Camp, H.J.M., Jetten, M.S.M., et al. (2011) Simultaneous nitrite-dependent anaerobic methane and ammonium oxidation processes. Appl Environ Microbiol 77: 6802-6807.

Luo, C., Rodriguez-R, L.M., Johnston, E.R., Wu, L., Cheng, L., Xue, K., et al. (2014) Soil microbial community Responses to a decade of warming as revealed by comparative metagenomics. Appl Environ Microbio/ 80: 1777-1786.

Mardanov, A.V., Beletsky, A.V., Kadnikov, V.V., Slobodkin, A.I., and Ravin, N.V. (2016) Genome analysis of Thermosulfurimonas dismutans, the first thermophilic sulfurdisproportionating bacterium of the phylum Thermodesulfobacteria. Front Microbiol 7: 950.

Morono, Y., Terada, T., Masui, N., and Inagaki, F. (2009) Discriminative detection and enumeration of microbial life in marine subsurface sediments. ISME J 3: 503-511.

Mulder, A., Graaf, A.A., Robertson, L.A., and Kuenen, J.G. (1995) Anaerobic ammonium oxidation discovered in a denitrifying fluidized bed reactor. FEMS Microbiol Ecol 16: 177-184.

Nawrocki, E.P. (2009) Structural RNA homology search and alignment using covariance models. PhD Thesis. St. Louis, MO: Washington University, Computational Biology.

Nurk, S., Meleshko, D., Korobeynikov, A., and Pevzner, P.A. (2017) metaSPAdes: a new versatile metagenomic assembler. Genome Res 27: 824-834.

Parks, D.H., Imelfort, M., Skennerton, C.T., Hugenholtz, P., and Tyson, G.W. (2015) CheckM: assessing the quality of microbial genomes recovered from isolates, single cells, and metagenomes. Genome Res 25: 1043-1055.

Price, M.N., Dehal, P.S., Arkin, A.P., and Poon, A.F.Y. (2010) FastTree 2 - approximately maximum-likelihood trees for large alignments. PLoS One 5: e9490.

R Development Core Team. (2017) R: A Language and Environment for Statistical Computing. Vienna, Austria: R Foundation for Statistical Computing.

Raghoebarsing, A.A., Pol, A., van de Pas-Schoonen, K.T., Smolders, A.J.P., Ettwig, K.F., Rijpstra, W.I.C., et al. (2006) A microbial consortium couples anaerobic methane oxidation to denitrification. Nature 440: 918-921.

Russ, L., Speth, D.R., Jetten, M.S.M., Op den Camp, H.J.M., and Kartal, B. (2014) Interactions between anaerobic ammonium and sulfur-oxidizing bacteria in a laboratory scale model system. Environ Microbiol 16: 3487-3498.

Sekiguchi, Y., Muramatsu, M., Imachi, H., Narihiro, T., Ohashi, A., Harada, H., et al. (2008) Thermodesulfovibrio 
aggregans sp. nov. and Thermodesulfovibrio thiophilus sp. nov., anaerobic, thermophilic, sulfate-reducing bacteria isolated from thermophilic methanogenic sludge, and emended description of the genus Thermodesulfovibrio. Int J Syst Evol Microbiol 58: 2541-2548.

Shi, Y., Hu, S., Lou, J., Lu, P., Keller, J., and Yuan, Z. (2013) Nitrogen removal from wastewater by coupling anammox and methane-dependent denitrification in a membrane biofilm reactor. Environ Sci Technol 47: 11577-11583.

Simon, J., Sänger, M., Schuster, S.C., and Gross, R. (2003) Electron transport to periplasmic nitrate reductase (NapA) of Wolinella succinogenes is independent of a NapC protein. Mol Microbiol 49: 69-79.

Slobodkina, G.B., Mardanov, A.V., Ravin, N.V., Frolova, A.A., Chernyh, N.A., Bonch-Osmolovskaya, E.A., et al. (2017) Respiratory ammonification of nitrate coupled to anaerobic oxidation of elemental sulfur in deep-sea autotrophic thermophilic bacteria. Front Microbiol 8: 87.

Solden, L.M., Hoyt, D.W., Collins, W.B., Plank, J.E., Daly, R.A., Hildebrand, E., et al. (2017) New roles in hemicellulosic sugar fermentation for the uncultivated Bacteroidetes family BS11. ISME J 11: 691-703.

Sorokin, D.Y., Tourova, T.P., Galinski, E.A., Muyzer, G., and Kuenen, J.G. (2008) Thiohalorhabdus denitrificans gen. nov., sp. nov., an extremely halophilic, sulfur-oxidizing, deep-lineage gammaproteobacterium from hypersaline habitats. Int J Syst Evol Microbiol 58: 2890-2897.

Strous, M., Heijnen, J.J., Kuenen, J.G., and Jetten, M.S.M. (1998) The sequencing batch reactor as a powerful tool for the study of slowly growing anaerobic ammonium-oxidizing microorganisms. Appl Microbiol Biotechnol 50: 589-596.

Taylor, S., Ninjoor, V., Dowd, D.M., and Tappel, A.L. (1974) Cathepsin B2 measurement by sensitive fluorometric ammonia analysis. Anal Biochem 60: 153-162.

Thorup, C., Schramm, A., Findlay, A.J., Finster, K.W., Schreiber, L., and Newman, D.K. (2017) Disguised as a sulfate reducer: growth of the Deltaproteobacterium Desulfurivibrio alkaliphilus by sulfide oxidation with nitrate. mBio 8: e00671-17.

Toro, E.E.R., and Cervantes, F.J. (2016) Coupling between anammox and autotrophic denitrification for simultaneous removal of ammonium and sulfide by enriched marine sediments. Biodegradation 27: 107-118.

van de Vossenberg, J., Woebken, D., Maalcke, W.J., Wessels, H.J.C.T., Dutilh, B.E., Kartal, B., et al. (2013) The metagenome of the marine anammox bacterium "Candidatus Scalindua profunda" illustrates the versatility of this globally important nitrogen cycle bacterium. Environ Microbiol 15: 1275-1289.

Wrighton, K.C., Thomas, B.C., Sharon, I., Miller, C.S., Castelle, C.J., VerBerkmoes, N.C., et al. (2012) Fermentation, hydrogen, and sulfur metabolism in multiple uncultivated bacterial phyla. Science 337: 1661-1665.

Wu, Y.-W., Simmons, B.A., and Singer, S.W. (2016) MaxBin 2.0: an automated binning algorithm to recover genomes from multiple metagenomic datasets. Bioinformatics 32: 605-607.

Xiao, Y., and Roberts, D.J. (2010) A review of anaerobic treatment of saline wastewater. Environ Technol 31: 1025-1043.
Zecchin, S., Mueller, R.C., Seifert, J., Stingl, U., Anantharaman, K., van Bergen, M., et al. (2017) Rice paddy Nitrospirae encode and express genes related to sulfate respiration: proposal of the new genus Candidatus Sulfobium. bioRxiv doi: 10.1101/196774.

Zhou, J., Bruns, M.A., and Tiedje, J.M. (1996) DNA recovery from soils of diverse composition. Appl Environ Microbiol 62: 316-322.

\section{Supporting information}

Additional Supporting Information may be found in the online version of this article at the publisher's web-site:

Fig. S1. Schematic overview of the contribution of individual microorganisms to elemental cycling in the bioreactor. Please see the main text for explanation and details.

Fig. S2. Maximum Likelihood phylogenetic tree using 17 concatenated ribosomal protein sequences. The topology was the same as found in the 16S rRNA gene tree.

Table S1. Overview of the FISH probes used to target specific microbial groups

Table S2. Comparison of genome bins obtained from the laboratory-scale bioreactor fed with ammonium, sulfide, nitrate and methane with previously published genome sequences identified by the locus identifier and gene annotation. MO, MN, A1 and A3: respective genome bin; NODE: contig number; length: contig length; cov: contig coverage; last underscore followed by digit: gene number.

Table S3. Analysis of a reconstructed genome (bin das_tool.binsanity.asm_contigs_metaspades_gt1500-bin_1-refined_1.fa or pSox1_ANNOTATED_contigs_1000.genes.fna) with metabolic potential for sulfur oxidation and nitrate reduction. This genome is $98.53 \%$ complete with $0.87 \%$ of contamination as estimated by analysis of single copy marker genes. The S3 ribosomal protein was $82.6 \%$ similar to the one in Sulfuricella denitrificans skB26. The genome coverage was 28 times, with $1.98 \%$ of assembled reads mapping to this bin, making it the 7th most abundant organism. pSox1: putative sulfur oxidizer number 1; NODE: contig number; length: contig length; cov: contig coverage; last underscore followed by digit: gene number; \% identity: amino acid percent similarity.

Table S4. Analysis of a reconstructed genome (das_tool.binsanity.asm_contigs_metaspades_gt1500-bin_18.fa or Nitrospirae_ANNOTATED_contigs_1000.genes.fna) with metabolic potential for oxygen reduction, sulfate reduction and nitrate reduction to nitrous oxide or ammonium. This organism was enriched and became the dominant microbial member in the bioreactor, representing a new group in the Nitrospirae phylum. Proteins of interest are highlighted in this table. NODE: contig number; length: contig length; cov: contig coverage; last underscore followed by digit: gene number.

Table S5. Average amino acid identity (AAI) table of the novel $\mathrm{Ca}$. Nitrobium versatile and its twenty closest representatives with available genome sequences. Nitrospina gracilis was used as an outgroup. 